\title{
Comparison of Body Mass Index Class Against Motor Performance Towards 7-Year-Old Boys in Malaysia
}

\author{
Nur Faizatul Amira Binti Jibril ${ }^{1 *}$, Mohamad Razali Abdullah², Ahmad Bisyri Husin \\ Musawi Maliki ${ }^{2}$, Intan Meily Puspitasari ${ }^{1}$, Nur Amirah Nawi ${ }^{1}$, Ahmad Nadzmi ${ }^{1}$, \\ Mohamad Amirur Rafiqi Zainoddin ${ }^{1}$ and Siti Hadiyanti Yuningsih ${ }^{3}$
}

\author{
${ }^{1}$ Faculty of Applied Science Social, University of Sultan Zainal Abidin, Kuala Nerus, 21300, Malaysia. \\ ${ }^{2}$ East Coast Environment Research Institute, 21300 University of Sultan Zainal Abidin Kuala Nerus, 21300, Malaysia. \\ ${ }^{3}$ Master Program in Mathematics, Faculty of Mathematics and Natural Science, Universities Padjadjaran, Indonesia \\ *Corresponding author. E-mail: amirajibril1109@gmail.com
}

\begin{abstract}
This research is conducted to study the comparison of Body Mass Index class against motor performance towards 7-year-old boys in Malaysia. This study will become guide to parents, government, dietitian and pediatrician to monitor the motor development process of 7-year-old kids. This study aims to compare the Body Mass Index (BMI) class against motor performance towards 7-year-old boys in Malaysia. 43646 of 7 years old boys in Malaysia were categorized into five groups based on BMI index value. Four motor performance tests (power, flexibility, coordination and speed) were evaluated in this study. The Multivariate Analysis of variance revealed that Body mass index (BMI) are significantly affected by all the variable of motor skill performance. The results of the analysis show that significantly, BMI is a factor in power [ $\mathrm{f}$ (717.84), $\mathrm{p}<.05$ ], flexibility [f (39.62), $\mathrm{p}<.05$ ], coordination [f (19.50), $\mathrm{p}<.05$ ] and speed [f (291.70), $\mathrm{p}$ $<.05]$. in other words, all the BMI variables of the 7-year-old boy in this study influenced all the variables. The value of R2 below the table indicates that BMI contributes only .062 or $6.2 \%$ change in variable dependent power, .004 or $0.4 \%$ change in variability based on flexibility, .002 or $0.2 \%$ change in coordination and 0.26 or $2.6 \%$ change in speed. Thus, the current study concluded that to improve motor skill, enhancement in each motor skill attributes should be considered instead of correcting BMI alone.
\end{abstract}

Keywords: BMI, Comparison, Motor performance

\section{INTRODUCTION}

One of the major public health issues globally is the high prevalence of infant obesity. Elevated children with BMI also mature as obese adults, and obese adults are more likely to develop certain conditions such as diabetes, cardiovascular disease, and some cancers [1]. A national Egyptian survey found a high prevalence of stunting and underweight in children [2]. In addition, South Africa and Brazil are among the deprived nations with high incidences of underweight and under nutrition in another study [3]. Analysis has shown that an underweight

individual is related to low bone mass and is due to mortality [4]. It has also been reported that a concomitant reduction in motor function capacity is associated with overweight [5]. Among the significant health markers, motor ability performance in children is considered [6].

Increased motor performance activity in childhood increased their cardiovascular and skeletal muscle wellbeing, reduced adiposity and had positive impacts on depression, anxiety, and academic achievement. Any variables in physical fitness are grouped into health-based variables (flexibility) and fitness skills (Power, flexibility, 
speed and coordination). Fitness is a gateway to day-today tasks. It is non-invasively detectable. Such health assessments can be used to measure the fitness elements. Observed the relation between weight category and exercise [7]. fitness as accepting morphology and metabolic members [8]. A big consideration for Body Mass Index (BMI) is the morphological predictor. BMI is primarily used in the study of childhood overweight and obesity. The volume and height of the body weight is used to calculate usually written BMI as; $(\mathrm{BMI}=\mathrm{kg} / \mathrm{m} 2)$. The BMI collection is based on break points collected from the general public and may not be unique to categories for young adults, infants or elderly people. Higher BMI levels have been shown to be accompanied by fatness which decreases optimum motor fitness efficiency whereas lower BMI levels are correlated with a lean body mass which induces high performance of motor fitness related variables [9]. For example, BMI was identified in adolescents as a factor correlated with physical health disparities [10]. BMI has been used as a symbol in the talent recognition sense for athletic success to recognize talent from an early age in the process of optimizing opportunities when the children are in their rising stages [11]. As such, the standard approach of screening children using their BMI has been successful in assessing the level of their ability for motor performance. Although several reports have found that children who are considered obese by BMI are unlikely to face any health problems from the start. Relationships between BMI level and general health and wellness were noticed, however. Yet the mutual interactions between motor fitness components and BMI are still imprecise. To our knowledge, systematically, the mutual interactions between components of motor ability health and form of BMI have rarely been reviewed. Thus, the present study aims to assess the motor performance of 7 years old boys in Malaysia on five separate classes of BMI (severe thinness, thinness, normal, overweight and obesity). The objective of this study is to identify the comparison of the development of gross motor performance on the Body Mass Index Class of 7-year-old boys in Malaysia.

\section{METHODOLOGY}

\subsection{Population}

The population of this study comprises 7-year-old boys in the Malaysia and Borneo peninsular primary schools. Such schools include national schools (SK), religious schools (SA), national schools of the Chinese type $(\operatorname{SJK}(\mathrm{C}))$, and national schools of the Tamil type (SKJ(T)).

\subsection{Participant And Testing Procedure}

Data from 43647 participants was composed of 7-year-old boys with 7 variables. Among the variables used are height, weight, BMI, standing broad jump, twenty-meter speed test, hand wall toasting and sit and reach. Once data analysis was performed, the researchers were first evaluating the data distribution. Data distribution is essential for deciding which data analysis should be used.

Parents, guardians, school administrators, and participants are granted this type of consent to clarify certain issues like study methods, research goals, and others. Participants agreeing to participate must voluntarily assist in data collection research. Within the consent form some main parts that participants must fulfill include personal data of participants and contact details; emergency contact information; health information and parent consent confirmation. This information is only available for research purposes. The researcher shall not reveal all personal information.

\subsection{Anthropometric Test}

Anthropometric testing includes weight and height standing height was measured with a wall-mounted wooden audiometer to the nearest 0.5 . Body weight was evaluated with a standardized electronic digital scale to the nearest $0.01 \mathrm{~kg}$. Body Mass Index is a simple calculation using a person's height and weight. The formula is BMI = $\mathrm{kg} / \mathrm{m} 2$ where $\mathrm{kg}$ is a person's weight in kilograms and $\mathrm{m} 2$ is their height in meters squared.

\subsection{Standing Broad Jump (SBJ)}

The participants have to stand behind a line marked on the ground with feet slightly apart. A two-foot take-off and landing were used, with swing the arms back and rhythmically bending the knees to about 90 degrees forward. The participants need to try to jump as far as possible, landing on both feet without falling backward. This test (SJB) will be cancelled if the participants making the mistake which is doing the double jumping and step on the line before jumping. Three trials were allowed and the furthest was considered.

\subsection{Twenty-Meter Speed Test (20MR)}

The participants running a single maximum sprint over a set range, with the recorded occasion. The distance between the starting point and the end was $20 \mathrm{~m}$. When either foot passed the starting point, the time began to count and completed once either foot passed the finishing point. Before the test, participants have to make sure the starting position should be standardized, starting from a stationary position with a foot back the starting point, without making any movements. By using stopwatch 
thing, the time to run each split distance $(20 \mathrm{~m})$ was measured.

\subsection{Sit and Reach (SAR)}

The participants sitting on the floor with straight legs, with heels on the floor and feet flat against the seat and reach the box. Both sides of the knees are held flat against the floor by the investigator if needed. With hands-on top of each other and palms facing down, the participants will then smoothly be reached forward with fingertips pushing the measuring slide across the measuring line as far as possible. The reach is heed for at least two seconds while the distance is taken. The investigator has to make sure there are no jerky movements and the fingertips remain level with the legs flat. Readings must be taken in multiples of $0.5 \mathrm{~cm} \mathrm{[12].}$

\subsection{Hand Wall Toss (HWT)}

The distance between the markers, it is $1 \mathrm{~m}$ away from the wall. The participants have to stands upright behind a marker line and facing the wall. The ball is thrown by one hand by making an underarm action against the wall and trying to catch the ball using the opposite hand. The ball is then thrown to the back of the wall and captured with the first hand. This test persists for 10 attempts. The number of throws that were caught will be recorded.

\subsection{Multivariate of Variance (MANOVA)}

With its multivariate analog, the MANOVA assumed that the entire that all variable has similar variances across groups [13]. Second, there is an added assumption that the relationships among the variable (similar to their correlations) are equivalent from one group to the next (that is, the pattern of correlations among the variables is the same from one group to another). On the interpretation side, and continuing with MANOVA example, there is an overall test of significance, which takes into account all of the variables and all of the groups. If this is significant, analysis have to perform separate ANOVAs on each variable, to see if any of data are significant individually. These ANOVAs must in to be followed up with other test to see which group differences are responsible.

MANOVA will be used by applying sequence of Pearson correlations were test between all of the dependent variable in order to test the assumption that the depend variable would be correlated with each other, at least in the moderate range. Additionally, covariance matrices were test the homogeneity for the purpose of the MANOVA.

\section{RESULTS AND DISCUSSION}

Multiple Analysis of Variance (MANOVA) was carried out across variables (power, flexibility, coordination and speed) with groups BMI (severe thinness, thinness, normal, overweight and obesity) to explore the differences among studied sample. Box's Test of Equality of Covariance Matrices in Table 1 below shows a significant result $(p<0.5)$. This indicates that the data deviates from one of the covariance equations conditions.

Table 1 Box's Test of Equality of Covariance Matrices.

\begin{tabular}{lr}
\hline Box's M & 453.38 \\
F & 11.33 \\
df1 & 40 \\
df2 & 120604480.29 \\
Sig. & 0.000 \\
\hline
\end{tabular}

Table 2 below show that there is a significant effect of significant BMI independent variables [f (212.623) = $21.62, \mathrm{p}<.05)$ on the four dependent variables as a whole.

Table 2 Multivariate Tests

\begin{tabular}{|c|c|c|c|c|c|c|}
\hline Effect & & Value & $F$ & Hypothesis df & Error df & Sig. \\
\hline \multirow[t]{4}{*}{ Intercept } & Pillai's Trace & .983 & $617248.414^{\mathrm{b}}$ & 4.000 & 43638.000 & .000 \\
\hline & Wilks' Lambda & .017 & $617248.414^{\mathrm{b}}$ & 4.000 & 43638.000 & .000 \\
\hline & Hoteling's Trace & 56.579 & $617248.414^{\mathrm{b}}$ & 4.000 & 43638.000 & .000 \\
\hline & $\begin{array}{l}\text { Roy's Largest } \\
\text { Root }\end{array}$ & 56.579 & $617248.414^{\mathrm{b}}$ & 4.000 & 43638.000 & .000 \\
\hline \multirow[t]{4}{*}{ Body Mass Index } & Pillai's Trace & .076 & 212.623 & 16.000 & 174564.000 & .000 \\
\hline & Wilks' Lambda & .924 & 218.847 & 16.000 & 133316.930 & .000 \\
\hline & Hoteling's Trace & .082 & 223.873 & 16.000 & 174546.000 & .000 \\
\hline & $\begin{array}{l}\text { Roy's Largest } \\
\text { Root }\end{array}$ & .078 & $848.064^{c}$ & 4.000 & 43641.000 & .000 \\
\hline
\end{tabular}


Levine's Equality of Error Variance test whether the variance of the dependent variables across the categories in the independent variable is the same. Test results show in Table 3 that three of the four dependent (power, flexibility, and speed) obtained significant results at $\mathrm{p}<.05$ (This variance test is required in the Step-down analysis procedure. Since this MANOVA test data analysis uses Enter analysis procedure, analysis can be continuing).

Table 3 Levene's Test of Equality of Error Variancesa

\begin{tabular}{lrccc}
\hline \multicolumn{1}{c}{ F } & & df1 & df2 & Sig. \\
\hline Power (cm) & 18.075 & 4 & 43641 & 0 \\
Flexibility (cm) & 52.213 & 4 & 43641 & 0 \\
Coordination (NO.) & 0.973 & 4 & 43641 & 0.421 \\
Speed (Sec) & 11.429 & 4 & 43641 & 0 \\
\hline
\end{tabular}

The results of the analysis in the previous Multivariate Test table show that overall, there is a major effect of BMI on the three dependent variables, then the main effect of each dependent variable can be identified in this Test of Between-Subjects Effects table. The results of the MANOVA test in this table show that there is a significant effect of BMI on all four dependent variables in this study. The results of the analysis show that significantly, BMI is a factor in power [ $\mathrm{f}(717.84), \mathrm{p}<.05$ ], flexibility [ $\mathrm{f}$ (39.62), $\mathrm{p}<.05$ ], coordination [f $(19.50), \mathrm{p}<.05$ ] and speed [ $\mathrm{f}$ (291.70), p<.05]. in other words, all the BMI variables of the 7-year-old boy in this study influenced all the variables.

The value of $\mathrm{R} 2$ below the table indicates that BMI contributes only .062 or 6.2 per cent change in variable dependent power, .004 or 0.4 per cent change in variability based on flexibility, .002 or 0.2 per cent change in coordination and 0.26 or 2.6 per cent change in speed.

The pairwise comparison results for the BMI independent variable confirm the results in the Test of BetweenSubjects Effect table above, that BMI is a factor to power, where the power score for the Normal BMI class outweighs other BMI classes (severe thinness, thinness, overweight and obesity). (mean difference: normal-obesity $=12.23, \mathrm{p}<.05$, after controlling Type I error using Bonferroni method)

Table 4 Tests of Between-Subjects Effects

\begin{tabular}{llccccc}
\hline Source & Dependent Variable & Type III Sum Of Squares & D $f$ & Mean Square & $F$ & Sig. \\
\hline Body & POWER $(\mathrm{Cm})$ & 972396.756 & 4 & 243099.189 & 717.842 & .000 \\
Mass & FLEXIBILITY $(\mathrm{Cm})$ & 4035.718 & 4 & 1008.929 & 39.621 & .000 \\
Index & COORDINATION (No.) & 664.788 & 4 & 166.197 & 19.454 & .000 \\
& SPEED (Sec) & 473.360 & 4 & 118.340 & 291.652 & .000 \\
& & & & & &
\end{tabular}

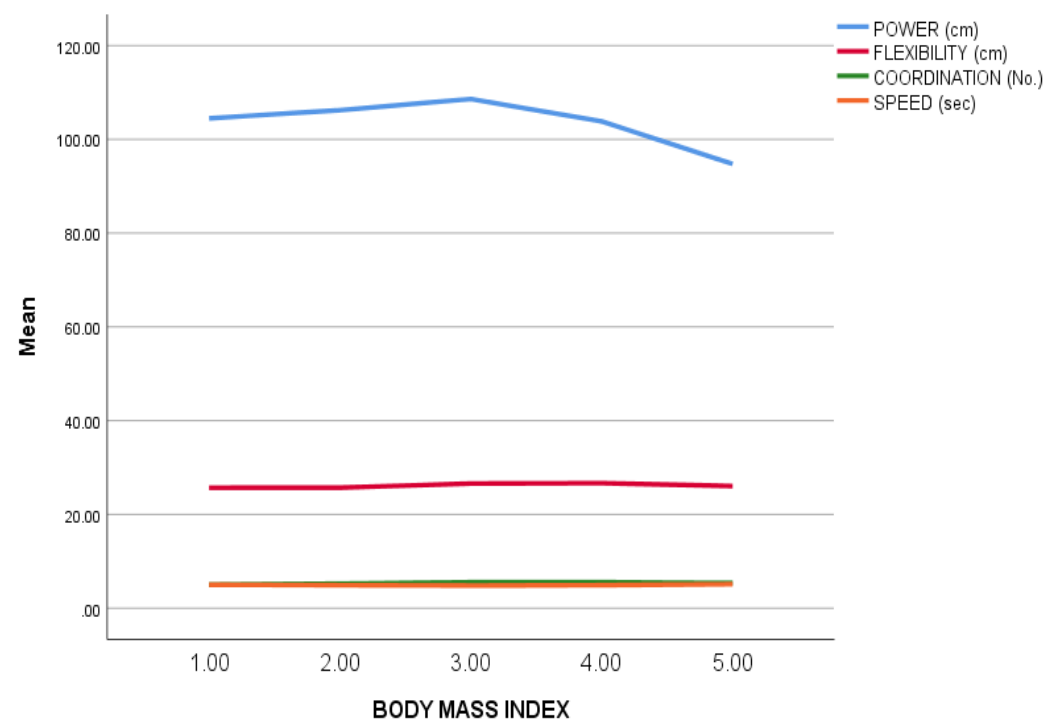

Figure 1 Mean graph for BMI among 7 years old boys in Malaysia. 
Table 5 Pairwise Comparison table

\begin{tabular}{|c|c|c|c|c|c|c|c|}
\hline \multirow{2}{*}{$\begin{array}{l}\text { Dependent } \\
\text { Variable }\end{array}$} & \multirow{2}{*}{$\begin{array}{l}\text { (I) BODY } \\
\text { MASS INDEX }\end{array}$} & \multirow{2}{*}{$\begin{array}{l}\text { (J) BODY MASS } \\
\text { INDEX }\end{array}$} & \multirow{2}{*}{$\begin{array}{c}\text { Mean Difference } \\
(\mathrm{I}-\mathrm{J})\end{array}$} & \multirow{2}{*}{$\begin{array}{l}\text { Std. } \\
\text { Error }\end{array}$} & \multirow{2}{*}{ Sig. ${ }^{b}$} & \multicolumn{2}{|c|}{$\begin{array}{l}95 \% \text { Confidence Interval } \\
\text { for Difference }\end{array}$} \\
\hline & & & & & & $\begin{array}{l}\text { Lower } \\
\text { Bound }\end{array}$ & $\begin{array}{l}\text { Upper } \\
\text { Bound }\end{array}$ \\
\hline \multirow{10}{*}{ Power $(\mathrm{cm})$} & \multirow{2}{*}{ Severe thinness } & Overweight & 0.659 & 0.596 & 1 & -1.014 & 2.333 \\
\hline & & Obesity & $9.721^{*}$ & 0.582 & 0 & 8.087 & 11.36 \\
\hline & \multirow{3}{*}{ Thinness } & Severe Thinness & 1.74 & 0.631 & 0.058 & -0.031 & 3.511 \\
\hline & & Overweight & $2.399^{*}$ & 0.435 & 0 & 1.178 & 3.621 \\
\hline & & Obesity & $11.461^{*}$ & 0.416 & 0 & 10.29 & 12.63 \\
\hline & \multirow{4}{*}{ Normal } & Severe Thinness & $4.130^{*}$ & 0.542 & 0 & 2.609 & 5.651 \\
\hline & & Thinness & $2.390^{*}$ & 0.357 & 0 & 1.387 & 3.393 \\
\hline & & Overweight & $4.789^{*}$ & 0.292 & 0 & 3.97 & 5.608 \\
\hline & & Obesity & $13.851^{*}$ & 0.262 & 0 & 13.12 & 14.59 \\
\hline & Overweight & Obesity & $9.062^{*}$ & 0.361 & 0 & 8.048 & 10.08 \\
\hline \multirow{10}{*}{$\begin{array}{l}\text { Flexibility } \\
(\mathrm{cm})\end{array}$} & \multirow{2}{*}{ Severe Thinness } & Overweight & $-.979^{*}$ & 0.163 & 0 & -1.438 & -0.52 \\
\hline & & Obesity & -0.352 & 0.16 & 0.276 & -0.8 & 0.096 \\
\hline & \multirow{4}{*}{ Thinness } & Severe Thinness & 0.012 & 0.173 & 1 & -0.473 & 0.498 \\
\hline & & Overweight & $-.966^{*}$ & 0.119 & 0 & -1.301 & -0.631 \\
\hline & & Obesity & $-.339^{*}$ & 0.114 & 0.029 & -0.659 & -0.019 \\
\hline & & Severe Thinness & $.893^{*}$ & 0.149 & 0 & 0.475 & 1.31 \\
\hline & \multirow{3}{*}{ Normal } & Thinness & $.880^{*}$ & 0.098 & 0 & 0.605 & 1.155 \\
\hline & & Overweight & -0.086 & 0.08 & 1 & -0.311 & 0.139 \\
\hline & & Obesity & $.541^{*}$ & 0.072 & 0 & 0.339 & 0.743 \\
\hline & Overweight & Obesity & $.627^{*}$ & 0.099 & 0 & 0.349 & 0.905 \\
\hline \multirow{10}{*}{$\begin{array}{l}\text { Coordination } \\
\text { (No.) }\end{array}$} & \multirow{2}{*}{ Severe Thinness } & Overweight & $-.530^{*}$ & 0.095 & 0 & -0.796 & -0.265 \\
\hline & & Obesity & $-.362^{*}$ & 0.092 & 0.001 & -0.621 & -0.102 \\
\hline & \multirow{4}{*}{ Thinness } & Severe Thinness & 0.217 & 0.1 & 0.307 & -0.065 & 0.498 \\
\hline & & Overweight & $-.314^{*}$ & 0.069 & 0 & -0.508 & -0.12 \\
\hline & & Obesity & -0.145 & 0.066 & 0.28 & -0.331 & 0.04 \\
\hline & & Severe Thinness & $.536^{*}$ & 0.086 & 0 & 0.294 & 0.778 \\
\hline & \multirow{3}{*}{ Normal } & Thinness & $.320^{*}$ & 0.057 & 0 & 0.16 & 0.479 \\
\hline & & Overweight & 0.006 & 0.046 & 1 & -0.125 & 0.136 \\
\hline & & Obesity & $.174^{*}$ & 0.042 & 0 & 0.058 & 0.291 \\
\hline & Overweight & Obesity & $.169^{*}$ & 0.057 & 0.033 & 0.008 & 0.33 \\
\hline \multirow{10}{*}{ Speed (sec) } & \multirow{2}{*}{ Severe Thinness } & Overweight & $.095^{*}$ & 0.021 & 0 & 0.037 & 0.153 \\
\hline & & Obesity & $-.128^{*}$ & 0.02 & 0 & -0.185 & -0.072 \\
\hline & \multirow{3}{*}{ Thinness } & Severe Thinness & $-.096^{*}$ & 0.022 & 0 & -0.157 & -0.034 \\
\hline & & Overweight & -0.001 & 0.015 & 1 & -0.043 & 0.042 \\
\hline & & Obesity & $-.224^{*}$ & 0.014 & 0 & -0.265 & -0.184 \\
\hline & \multirow{4}{*}{ Normal } & Severe Thinness & $-.175^{*}$ & 0.019 & 0 & -0.227 & -0.122 \\
\hline & & Thinness & $-.079^{*}$ & 0.012 & 0 & -0.114 & -0.044 \\
\hline & & Overweight & $-.079^{*}$ & 0.01 & 0 & -0.108 & -0.051 \\
\hline & & Obesity & $-.303^{*}$ & 0.009 & 0 & -0.328 & -0.277 \\
\hline & Overweight & Obesity & $-.224^{*}$ & 0.013 & 0 & -0.259 & -0.188 \\
\hline
\end{tabular}




\section{CONCLUSION}

The discussion on the findings of the study presented in this chapter is appropriate in achieving the objectives of the study that has been decided. Researchers are hoping this research will help those involved and apply it to the current situation and inherit future generations.

\section{ACKNOWLEDGMENT}

The University of Sultan Zainal Abidin (UniSZA) has collaborated with the National Sports Institute (ISN) to obtain information on physical fitness among children. A grant for this research was given by the National Sport Institute (ISN). The full funding for this research is given by this institute. For the success of this study, the researchers would like to thank parents, guardians, school authorities and participants for their good cooperation.

\section{REFERENCES}

[1] C. J. Jolliffe, I Janssen. Vascular risks and management of obesity in children and adolescents .Vascular Health and Risk Management, 2 (2) (2006) 171. DOI: https://doi.org/10.2147/vhrm.2006.2.2.171

[2] S. Singh, S. Srivastava, A. K. Upadhyay. Socioeconomic inequality in malnutrition among children in India: an analysis of 640 districts from National Family Health Survey (2015-16). International journal for equity in health, 18 (1) (2019) 1-9.

[3] A. L. Sawaya, P. Martins, D. Hoffman, S. B. Roberts. The link between childhood undernutrition and risk of chronic diseases in adulthood: a case study of Brazil. Nutrition reviews, 61 (5) (2003) 168-175. DOI: https://doi.org/10.1301/nr.2003.may.168-175

[4] K. P. Sreekumar, P. J. Sharp. Ontogeny of the photoperiodic control of prolactin and luteinizing hormone secretion in male and female bantams (Gallus domesticus). General and comparative endocrinology , 109 (1) (1998) 69-74. DOI: https://doi.org/10.1006/gc en.1997.7009

[5] G. R. Tomkinson, T. S. Olds, S. J. Kang, D. Y. Kim. Secular trends in the aerobic fitness test performance and body mass index of Korean children and adolescents (1968-2000). International journal of sports medicine, 28 (04) (2007) 314-320. DOI: 10.1055 /s-2006-924357
[6] F. B. Ortega, J. R. Ruiz, M. J. Castillo, M. Sjöström. Physical fitness in childhood and adolescence: a powerful marker of health. International journal of obesity, 32 (1) (2008) 1-11.

[7] A. M. Lasserre, A. Chiolero, F. Cachat, F. Paccaud, P. Bovet. Overweight in Swiss children and associations with children's and parents' characteristics .Obesity, 15 (12) (2007) 2912-2919. DOI: https://doi.or g/10.1038/oby.2007.347

[8] C. Acasuso-Rivero, C. J. Murren, C. D. Schlichting, U. K. Steiner. Adaptive phenotypic plasticity for lifehistory and less fitness-related traits. Proceedings of the Royal Society B, 286 (1904) (2019) 20190653. DOI: https://doi.org/10.1098/rspb.2019.0653

[9] I. Esteban-Cornejo, M. Rodriguez-Ayllon, J. Verdejo-Roman, C. Cadenas-Sanchez, J. MoraGonzalez, L. Chaddock-Heyman, C. H. Hillman. Physi cal fitness, white matter volume and academic perform ance in children: findings from the Active Brains and FITKids2 projects. Frontiers in psychology, 10 (2019) 208. DOI: https://doi.org/10.3389/fpsyg.2019.00208

[10] I. Niederer, S. Kriemler, L. Zahner, F. Bürgi, V. Ebenegger, P. Marques-Vidal, J. J. Puder. BMI grouprelated differences in physical fitness and physical activity in preschool-age children: a cross-sectional analysis. Research quarterly for exercise and sport, 83 (1) (2012) 12-19. DOI: https://doi.org/10.1080/027013 67.2012.10599820

[11] C. E. Gonçalves, L. M. Rama, A. B. Figueiredo. Talent identification and specialization in sport: an overview of some unanswered questions. International journal of sports physiology and performance, 7 (4) (2012) 390-393. DOI: https://doi.org/10.1123/ijspp.7.4 .390

[12] A. B. H. M. Maliki, M. R. Abdullah, A. Nadzmi, M. A. R. Zainoddin, I. M. Puspitasari, N. F. A. Jibril, S. K. S. Ali. Kids motor performances datasets. Data in brief, 34 (2021) 106582. DOI: https://doi.org/10.1016/j .dib.2020.106582

[13] M. J. Anderson. A new method for non-parametric multivariate analysis of variance. Austral ecology, 26 (1) (2001) 32-46. DOI: https://doi.org/10.1111/j.14429993.2001.01070.pp.x 